\title{
Accelerating reproductive and child health program development: The Navrongo initiative in Ghana
}

\author{
James F. Phillips \\ Population Council \\ Ayaga A. Bawah \\ Population Council
}

Fred N. Binka

Follow this and additional works at: https://knowledgecommons.popcouncil.org/departments_sbsr-pgy

Part of the Demography, Population, and Ecology Commons, Family, Life Course, and Society Commons, and the International Public Health Commons How does access to this work benefit you? Let us know!

\section{Recommended Citation}

Phillips, James F., Ayaga A. Bawah, and Fred N. Binka. 2005. "Accelerating reproductive and child health program development: The Navrongo initiative in Ghana," Policy Research Division Working Paper no. 208. New York: Population Council. 


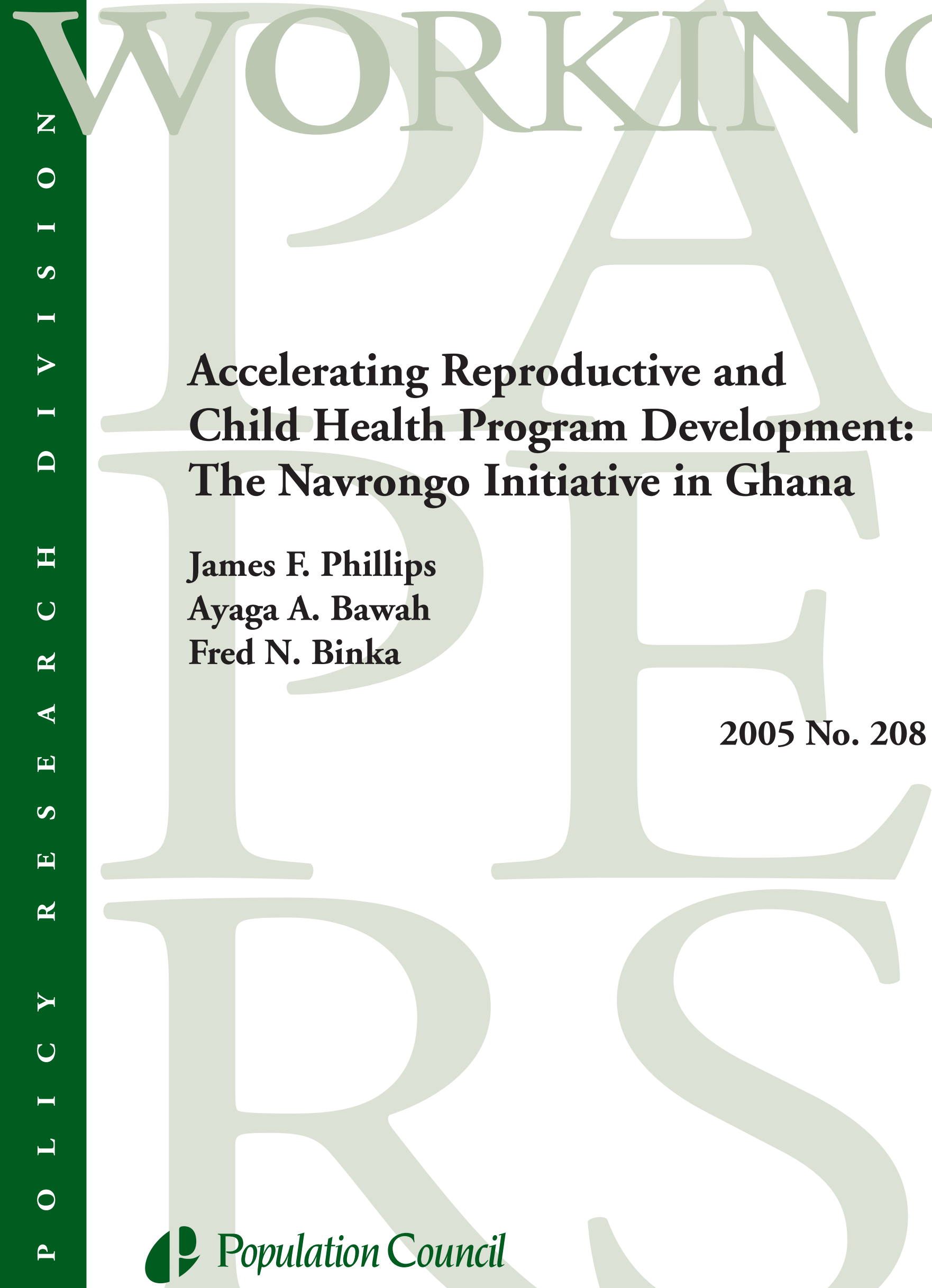




\section{(P) Population Council}

One Dag Hammarskjold Plaza

New York, New York 10017 USA

www.popcouncil.org

pubinfo@popcouncil.org

This material may not be reproduced without written permission from the authors. For a list of Policy Research Division Working Papers, including those that are currently available for downloading in PDF format, see www.popcouncil.org/publications/wp/prd/rdwplist.html.

ISSN: $1554-8538$

(C) 2005 The Population Council, Inc. 


\title{
Accelerating Reproductive and Child Health Program Development: The Navrongo Initiative in Ghana
}

\author{
James F. Phillips \\ Ayaga A. Bawah \\ Fred N. Binka
}

James F. Phillips is Senior Associate and Ayaga A. Bawah is Berelson Fellow, Policy Research
Division, Population Council. Fred N. Binka is Executive Director, INDEPTH-Network, Accra,
Ghana.

This research was funded by grants to the Navrongo Health Research Centre for its Demographic Surveillance System from the Rockefeller Foundation and the National Institutes of Health. The Community Health and Family Planning Project has been funded by grants to the Population Council from the United States Agency for International Development and the Finnish International Development Agency. 


\begin{abstract}
Successive global health and development agendas have been embraced by African governments-Alma Ata in 1978, the Bamako Initiative in 1987, the 1994 Cairo International Conference on Population and Development, and more recently, the Millennium Development Goals (MDGs) - only to be followed by widespread implementation failure. This paper presents an approach to program development in Ghana that is using research to accelerate policy implementation. Originally launched in 1994 as a participatory pilot project of the Navrongo Health Research Centre, a controlled experimental study was initiated in 1996 to assess the fertility and child-survival impact of alternative community health and family planning service strategies. Posting nurses to communities reduced childhood mortality rates by half, accelerating attainment of the childhood-survival MDG within five years. Adding community- mobilization strategies and volunteer outreach to this approach led to a 15 percent reduction in fertility. When a replication project in the Volta Region demonstrated that the Navrongo service model could be transferred to a nonresearch setting, the Government of Ghana adopted the Navrongo approach as the health component of its national poverty-reduction strategy. In 2000, the Community-based Health Planning and Services (CHPS) initiative was launched to accelerate implementation of this policy. By mid-2005, CHPS was fully operational in 20 districts and under development in nearly every other district of Ghana. Analysis of successive phases of the Ghana programdevelopment process demonstrates feasible means of improving national access to reproductive and child health services.
\end{abstract}


Since the 1978 Conference on Primary Health Care held at Alma Ata, USSR, establishing "health for all" has been a priority of most African governments. Yet, as the new millennium approached, accessible health care in their community remained a distant dream for most African households. Expanding access to comprehensive reproductive health services has also been a priority of African governments since the 1994 International Conference on Population and Development (ICPD) held in Cairo. Despite more than a decade of governments' commitment to the Cairo agenda, concern is mounting that reproductive health programs in the region are not working. What to do to about problems of implementation remains the subject of renewed international discussion and debate throughout the region in light of recent evidence that no African country is achieving the child-survival Millennium Development Goal (MDG). This paper presents lessons learned from an initiative undertaken by the Navrongo Health Research Centre (NHRC) in northern Ghana. The Navrongo initiative was launched to help resolve international health-policy debate, and it used evidence generated in the Navrongo setting to guide national efforts to develop community-based reproductive and child health services.

\section{The NAVRongo INITIATIVE}

The Navrongo initiative was launched to guide Ghana's health-reform process rather than to produce research as an end product. Convened by the Ministry of Health's Director General of Medical Services in response to mounting evidence that the health program was failing to reach the rural poor (Ministry of Health 1998), a policy committee reviewed the relative merits of two alternative strategies for providing community health care-volunteer-based care that could extend the availability of essential services at low cost versus professional community nursing and paramedical services. A protocol was developed for testing strategies that would simultaneously address health- and population-policy issues.

\section{The health-policy debate}

The Navrongo process was launched to resolve policy debate about the relative healthcare development value of volunteer-versus-professional paramedic approaches to community health-service delivery.

A perspective endorsed by the UNICEF/WHO-sponsored Bamako Initiative emphasized the potential value of augmenting clinical services with community-based volunteer health services. Established by a consensus established during a 1987 conference of African ministers of health, the Bamako Initiative sought to translate the social institutions that organize African daily life into resources for organizing, financing, and sustaining community health services. Using the Bamako approach, program managers focused resources on recruiting community health-care volunteers, organizing community supervision of their work, and providing initial essential health-care resources that communities would sustain through user fees and revolving accounts (Knippenberg et al. 1990; UNICEF 1991 and 1995). The initiative soon became controversial, however, when evaluation research revealed mixed results (McPake et al. 1993). In Ghana, for example, the volunteer component of the Bamako strategy was controversial as a result of high volunteer turnover, poor quality of care, and lapses in supervision that led to problems with community financing (Adjei et al. 1995). 
An alternative view, embraced by the World Bank and by some World Health Organization special programs, advocated the use of paid professional nurses for improving the range and coverage of community health care (Berman et al. 1987; World Bank 2003). Although a widespread consensus developed that existing and low-cost health technologies could reduce substantially the burden of childhood illness and that incremental health-service resources were needed, international health-care development agendas were promoted without specific evidence clarifying the means of making essential health-care technology and resources available to communities (World Bank 1993). Trials that demonstrate practical means of making these technologies and resources available locally are urgently needed (Bryce et al. 2003).

Ghana responded to international health-care development initiatives with locally tailored policies and programs. Some elements of the Bamako package were adopted as national policy, such as user fees and revolving accounts for essential drugs, but the cost of community nurses' salaries, training, and basic equipment was covered by the government program. By 1992, more than 2,000 community health nurses had been hired, trained for 18 months, and posted to districts throughout Ghana. The program encountered serious operational pitfalls, however, relating to a shortage of funds for the construction of community clinics and to other logistical problems. Lacking community facilities where nurses could work and live, the program posted all nurses to subdistrict health centers more than 10 kilometers, on average, from the rural households they were serving. They were community workers in name only (Agyepong and Marfo 1992).

\section{The population-policy debate}

For decades, questions about the demographic role of African family planning services have been the subject of policy debate (Caldwell and Caldwell 1987 and 1988). Although fertility has declined in East and Southern Africa, Sahelian West African fertility rates are double the rates observed elsewhere in the developing world. Variants of successful Asian models for developing reproductive health services have been advocated for Africa, such as community distribution of contraceptive supplies, but research in the region has provided compelling evidence that results obtained in Asia would not be replicable in Africa (Caldwell and Caldwell 1987 and 1988; van de Walle and Foster 1990; Simmons 1992; Pritchett 1994). Although contraceptive distribution was associated with increased contraceptive prevalence in several demonstration projects, research also showed that modern method adoption in rural Africa often works as a substitute for traditional fertility regulation rather than as a means of reducing fertility per se (Bledsoe et al. 1994). Large-scale family planning programs were, nonetheless, launched and funded throughout the region, often with guidance gleaned from research. A common but untested assumption concerned the proposition that accessible family planning services would reduce fertility by reducing the geographic cost of method adoption. A related perspective emphasized the potential impact of offsetting the social costs of contraception-spousal, familial, and cultural factors that prevent individuals from implementing their personal preferences (Easterlin 1978; Easterlin and Crimmins 1985). By the time of the 1994 Cairo conference, a global consensus had emerged calling for a shift in national population agendas from their demographic focus to gender-based strategies that addressed a wide range of 
reproductive health needs. Little systematic evidence was available, however, demonstrating how this consensus could be implemented in African countries.

The population-policy debate in Ghana was shaped by international controversy and dialogue. First, no evidence indicated that programs of any kind would have an impact on fertility. Moreover, a consensus existed among senior policy leaders that reproductive health services were not reaching the rural poor, but no consensus was formed on how this problem could be addressed, apart from an understanding that the resources and mechanisms of the Ministry of Health could be better used to establish a fully functioning community health program for expanding access to reproductive and child health services. The Navrongo experiment was launched to clarify strategic options for this community health program, to determine the impact of particular approaches on reproductive and child health indicators, and to generate evidence for guiding the national health-care-reform process.

\section{Experimental cells}

The project site was located in a isolated rural area of northern Ghana. The study area, Kassena-Nankana District, lies in Ghana's most impoverished region, ensuring that any project success demonstrated in that locality could not be dismissed as a mere by-product of favorable circumstances. Baseline mortality rates were well above national levels. Cultural traditions were known to sustain high fertility (Adongo et al. 1997). The economy in the study area was dominated by subsistence agriculture; literacy was low (particularly among women); and traditions of marriage, kinship, and family-building emphasized the economic and security value of large families. Health-care decisionmaking was strongly influenced by traditional beliefs, animist rites, and poverty. Parental health-care-seeking behavior was governed more by tradition than by awareness of modern health-care options.

Responding to the need to resolve debate with research, the Ghana Ministry of Health developed a process for organizational change comprised of stages guided by successive generations of questions rather than of discrete research projects for producing stand-alone end products. This process of generating and using evidence is illustrated in the overlapping phases depicted in Figure 1. In Phase I, a Navrongo micropilot community-health-service implementation was conducted in conjunction with continuous social research for gauging needs and reactions to services rendered. Its goal was to clarify steps in implementing and tasks in managing community health care. Phase II tested the hypothesis that experimental strategies reduced fertility and mortality by extending approaches developed in the pilot to a districtwide experimental trial. Phase III tested the transferability of Navrongo strategies to Nkwanta District in the Volta Region with the goal of building policy consensus that the Navrongo model was replicable. Phase IV, launched in 2000 , is a national program of policies, plans, and actions that comprise the Community-based Health Planning and Services (CHPS) initiative. Each phase was designed to respond to the next generation of questions as the process unfolded, each requiring contrasting research approaches as the process progressed. 


\section{Phase I: The Participatory Pilot}

A three-village program of social research and strategic planning was launched in 1994 for which villagers were consulted about appropriate ways to organize, staff, and implement primary-health-care and family planning services. Community dialogue about pilot service delivery was initiated to engage chiefs, elders, and women's groups about the importance of supporting community health-care service delivery (Nazzar et al. 1995). Particular attention was directed to the importance of communities' contribution of labor and materials for constructing health compounds where nurses were to be posted. The mechanics of launching this program and listening to its stakeholders generated practical insights into ways of changing programs from clinic-focused services to community-based care. These steps were clarified by modifying the program over time and reconvening focus-group discussions with pilot-community members to gauge their reactions and garner their advice. Some of the lessons that emerged from this phase are described below.

\section{Community participation and leadership}

Communities will donate labor for constructing health compounds if they can trust the program to provide nurses once the work is completed. Community investment, in turn, generates sustained community interest and involvement in the program.

Community leaders can be mobilized to support primary-health-care and family planning services. The process of mobilization encourages male involvement and reduces social tension concerning the promotion of reproductive health care and family planning services. Community leaders can reinforce and sustain supervision of health-care services.

\section{Support systems for community nurses}

Nurses may be relocated to communities, but their social isolation, work challenges, and daily living needs require sustained community and supervisory support and outreach to their spouses. Councils of chiefs and elders will assemble committees to take responsibility for this support.

\section{Gender and social impact}

The Kassena and Nankana peoples of northern Ghana have marriage and family-building customs that impose a social structure of male dominance and the notion of women as male property acquired through the tradition of bridewealth for the purpose of producing children for the lineage (Adongo et al. 1997). In this setting, where collective values are paramount, the male power system can be co-opted for the development of gender equity. Promoting family planning without addressing gender issues generates social discord (Bawah et al. 1999). Chiefs are open to sponsoring durbars (public gatherings) and other traditions for the purpose of promoting family planning, thereby putting men at ease and enabling women to assert unprecedented reproductive autonomy. 


\section{Increasing access to health care}

Community-based paramedical care increased the volume of services sixfold in pilot communities, requiring adjustment to pharmaceutical fee policies. Community care dramatically improved immunization coverage and expanded the range and quality of reproductive and ambulatory health care. Women's strong preference for injectable contraceptives was addressed by doorstep and compound-based paramedical services. If convenient nurse services are combined with community mobilization, health-care and immunization coverage will improve and family planning practice will increase.

\section{Phase II: The Navrongo Experiment}

The experimental design that emerged from the pilot evaluated strategies for making use of existing resources of health services and social institutions, minimizing the need for additional funding for operational support (Binka et al. 1995). Two broad categories of resources were mobilized by the design, each corresponding to domains of the policy debate.

The "community health officer dimension" reoriented existing community health nurses to community health care and assigned these retrained paramedics to village locations as upgraded personnel, newly designated as community health officers (CHOs). Nurses entering the program were trained for 18 months in national training institutions and intensively for six weeks in methods of community engagement. National policies stipulated that these nurses would be based within communities, but logistical problems hampered the plans for their deployment. The Phase I community dialogue focused on this problem and generated ideas about how to proceed. Chiefs and elders agreed to convene community gatherings to seek volunteer support for constructing dwelling units, using local designs, materials, and resources. Once these compounds were constructed, nurses were posted to the community. The program supported all the nurses' training, essential equipment, and start-up pharmaceuticals, but each community was obligated to maintain the facility, provide security, and support the nurse's daily living needs. The CHO arm of the experiment was designed to improve geographic access to care. Nurses were provided with motorbikes and trained to provide household outreach services in addition to convenient compound-based care during well-publicized hours of duty.

The "zurugelu ('from the people') dimension" mobilized cultural resources of chieftaincy, social networks, village gatherings, volunteerism, and community support. Whereas community liaison in the $\mathrm{CHO}$ dimension focused on starting the program, liaison in the zurugelu arm was continuous, involving regular community gatherings, male volunteers, community-network mobilization, and other activities designed to integrate project management into the traditional system of social organization. A prominent feature of the zurugelu dimension was its gender component, activities designed to build male leadership, ownership, and participation in reproductive health services and to expand women's participation in community activities that traditionally have been the purview of men. This social-action agenda was designed to enhance the autonomy of women in seeking reproductive and child health care, thereby reducing the social costs of women's participation in the program. The zurugelu system extended to Navrongo communities the Bamako Initiative's model for recovering the cost of essential drugs by equipping volunteers with bicycles, with a start-up kit of essential drugs, and with training in 
managing services and revolving accounts so that the flow of supplies would be sustainable and financed by the community.

Because the two dimensions can be mobilized independently, jointly, or not at all, a fourcelled experiment was implied by the design. The joint-implementation cell tested the impact of mobilizing community-based health care through traditional institutions combined with referral support and resident ambulatory care provided by CHOs. All cells, including the comparison area, were provided with subdistrict clinical services, equivalent densities of staff, and equivalent access to supplies and technical training.

The Navrongo experiment was configured with geographic zones corresponding to cells of the design, each representing alternative intensive, low-cost, and comprehensive servicedelivery operations. A demographic surveillance system that monitors births, deaths, migration, and population relationships was used to assess the impact on fertility and mortality of alternative strategies for providing community health services. The four subdistrict health-center zones of Kassena-Nankana District were randomly assigned to one of four cells, defining contiguous geographic zones of a factorial experiment (see Figure 2).

The project is formally categorized as a "plausibility design" rather than as a true experimental study (Habicht et al. 1999). Nonetheless, research systems of the Navrongo Centre provided an element of rigor that would not be obtainable with a simple cross-sectional comparison (Victora et al. 2004). The study district was equipped with a longitudinal demographic surveillance system for assessing experimental program impact. This system recorded all vital events, persons at risk, and relationships of members of extended households for the 139,000 rural residents of the district (Binka et al. 1999). Survival analyses controlled pre-experimental cluster differentials; fertility-impact assessment was adjusted for individual reproductive patterns prior to program exposure. Saturation sampling, moreover, eliminates sampling error, and prospective monitoring eliminates recall biases associated with survey research. For this reason, the Navrongo experiment is an unusually rigorous quasi-experimental assessment of the impact of community health services.

\section{Fertility impact}

Over the 1997-2003 period, the Navrongo experiment exhibited a pronounced fertility impact (Debpuur et al. 2002). On average, total fertility rates in cell 3 of the experiment were one full birth less than those expected in the absence of the intervention. Results have been regression-adjusted for the possible confounding effects of cellwise fertility differentials, educational attainment, and marriage type. Cell 3 effects persist after adjustment, supporting the hypothesis that the supply of family planning services can have an impact, even in an impoverished traditional rural African setting (Phillips et al. 2003).

Baseline research showed that unmet need for contraception in the study area was almost entirely related to demand for birth spacing and that nearly half of all women were either amenorrheic, separated from their spouses, or otherwise not at risk of becoming pregnant. Few women expressed the view that childbearing should be ended according to individual volition or through family planning. Research demonstrated a strong association, however, between stated desires to space fertility and spacing behavior. Spacing preferences are relevant to women of all 
ages, and project impact reflects this underlying climate of demand for family planning. Contraceptive-method adoption typically is a means of substituting for traditional fertility regulation, but it is also a means of providing the option of birth spacing that would not otherwise be available. Figure 3 shows the implications of this climate of demand for family planning. In each five-year age group, fertility declined in experimental cell 3 (Figure 3a) relative to the comparison area (3b), where it did not decline.

Findings demonstrate the importance of prospective demographic surveillance and fertility endpoints for assessing the project's impact. Although observed trends in cell fertility differentials are consistent with reported contraceptive-use trends, the reported level of contraceptive use is a third lower than would be expected in light of the levels of fertility decline reported to the demographic surveillance system. Research suggests that this discrepancy is, in part, the result of the tendency of contraceptive users to deny that they are using a method when they are interviewed about reproductive practices. Spousal secrecy about use clearly biases survey responses. Secrecy about contraception was also evident in clinical encounters, reflected by women's tendency to prefer methods that they can readily use clandestinely. Fully 92 percent of all women reporting contraceptive use in the Navrongo experiment said they were using an injectable contraceptive, and 5 percent had adopted the hormonal implant Norplant ${ }^{\circledR}$. Thus, neither oral contraceptives nor condoms were acceptable to the study population, even when these methods were easily accessible from community nurses and volunteer providers.

Results of the experiment changed with time in ways that demonstrate the concept of "fragile demand." In 1999, for example, the Government of Ghana instituted a policy of "exemptions," whereby children younger than five and pregnant women were entitled to free pharmaceuticals. This untested policy was instituted in the context of the Navrongo experiment, which had operated until that time with a user fee for cost-recovery. Because community services were accessible and the volume of clinical encounters had been increased by community nursing, stocks of essential drugs were depleted quickly, leading to a breakdown in community service operations in cells 2 and 3 for a period of nine months. This disruption was associated with a dramatic decline in contraceptive use and an increase in the total fertility rate of 0.5 births occurring nine months following the interruption. The dependency of couples on reliable services demonstrates the concept of fragile demand, whereby intermittent use is more common than sustained use in areas where social support for contraception is weak and spousal support may be inconsistent or lacking.

The study's findings demonstrate that achieving an impact on fertility requires that accessible services be established with a well-developed mechanism for offsetting the social costs of fertility regulation. The community-engagement strategies in the zurugelu arm of the project were designed to build male involvement in the program. More than 80 percent of the volunteers were men, and most community activities in cells 1 and 3 were focused on nurturing the participation of traditional leaders and heads of kinship groups and of extended families in the promotion of health-care and family planning. Community-engagement activities also involved individual women and women's social networks. The combined effect of outreach to men and women reduced gender stratification in reproductive decisionmaking. In experimental cell 2, however, where nurses were posted to communities without continuous zurugelu activities and community action was directed solely to health promotion and to the construction of health 
compounds, making family planning care and commodities accessible had no impact. The contrasting impact of the experimental arms of the Navrongo experiment demonstrated, therefore, that male engagement was crucial to achieving success.

No evidence was found that the Navrongo experiment induced a fertility transition. Longterm observation of differential effects according to cells shows that early experimental effects have remained constant over time. Although the project's activities generated preferences for limiting fertility, the new climate of demand for family planning has yet to translate into an expanding and sustained fertility transition of the sort that has been observed in Asia. Results suggest that developing family planning and health services will have the intended effects, but cannot solve the problem of high fertility in a rural African setting in isolation from other social, economic, or health developments.

\section{Child-survival impact}

Although the past several decades have witnessed an overall decline in rates of child mortality in developing countries, recent United Nations reports suggest considerable variation in the rate of progress both within and between regions. Mounting evidence of stagnation and reversal of gains achieved during the 1970s and 1980s is a growing concern. This situation is particularly true of sub-Saharan Africa, which accounts for over half of all deaths of children younger than five. Obstacles to the achievement of the Millennium Development Goal (MDG) of reducing under-five mortality to two-thirds of its current levels include the poor performance of many African economies, the continued prominence of preventable illnesses such as malaria, tuberculosis, and diarrhea, and the emergence of HIV/AIDS (Hill 1993; Nicoll et al. 1994; Caldwell 1997; Timaeus 1997, 1999a, and 1999b). The recent upswing in mortality signals an urgent need to rethink strategies for promoting child survival. Lessons from the Navrongo experiment are relevant to policy deliberations on achieving the MDG.

The district in the Upper East Region of Ghana where the Navrongo Health Research Centre is located is achieving the child-survival MDG, whereas Ghana as whole lags behind. For Ghana, recent Demographic and Health Survey (GDHS) results show that national gains in child survival have stalled and that decreases in infant and child mortality have been reversed in all regions of the country except the Upper East Region. Although the national infant mortality rate declined progressively from 77 deaths per 1,000 live births in 1988 to 57 deaths in 1998, it climbed back to 64 deaths in 2003. Similarly, although under-five mortality dropped from 155 in 1988 to 108 in 1998, it rose again to 111 in 2003. In the Upper East Region, however, progress achieved in the 1980s and 1990s continued. According to the 2003 GDHS, the infant mortality rate in this region has declined consistently, from 85 deaths in 1993 to 33 deaths in 2003. Moreover, the under-five mortality rate of the region declined from 188 in 1993 to 79 in 2003 (Ghana Statistical Services et al. 2004) despite the fact that the Upper East is Ghana's poorest and most remote region. Health-care programs in the region may explain the observed trend, however. Analysis of the first three years of Navrongo project exposure shows that child-health interventions have had a pronounced impact on child mortality (Pence et al. 2005). Other studies have demonstrated dramatic effects on child mortality from insecticide-impregnated bednets (Binka et al. 1996) and other health interventions (Ghana Vitamin A Supplementation Team 
1993). When research results from the Navrongo Centre were used to guide national health policy, the Upper East Region worked most intensely to scale up community health services (Nyonator et al. 2005a). At the time of the GDHS, more CHPS nurses were deployed to communities in the Upper East Region than to any other region of the country. The combined effect of various intervention activities reduced child mortality in the study district below the level set by the MDG for 2015 and reached the goal in 2004 (see Figure 4).

Posting nurses to communities accelerates progress in achieving the MDG, whereas developing volunteer services has no impact on child survival. Although child mortality declined throughout Kassena-Nankana District, including the comparison areas, declines were more pronounced in communities where nurses were assigned (Binka et al. 2005). Where volunteers worked without a nurse, trends followed the same trajectory as in comparison areas, indicating that volunteers made no contribution to child survival (see Figure 5). This finding is corroborated by qualitative research on parental health-care-seeking behavior. For impoverished families, parents dealing with childhood illness tend to seek care first from traditional healers because deferred payment customs and social arrangements make traditional healing a more feasible option than clinical care. Volunteers lack the credibility to change this dynamic, whereas community nurses substitute for traditional healers. Nurses working in concert with chiefs and elders develop social insurance mechanisms that elude other modern health-care providers. In providing a range of health-care services, community nurses introduce major means of making gains in child survival. Although volunteers made no contribution to child survival during the study, they contributed to the intervention's reproductive health impact. Therefore, cell 3 has been adopted as the service model for the national health program. Research demonstrates that by adopting this strategy, the Navrongo experiment enabled the project area to achieve the childsurvival MDG within five years (see Figure 6).

\section{Phase III: Replicating The NaVRongo ExPeriment}

Beginning in 1999, Nkwanta District in the Volta Region served as a demonstration ground for developing and testing practical means of transferring the Navrongo model of community health services to other districts. Tools were developed for monitoring impact through survey research (Awoonor-Williams et al. 2004). Qualitative research was conducted to gauge reactions to the program, note progress, and diagnose problems (Nyonator et al. 2005b). The research was designed to be a minor component of budgets, and implementation activities were limited to actions that could be taken using existing staff and financial resources. The phasing in of community health care by nurse-service zone resulted in variation in exposure to the program that was used in survey research to gauge the program's impact. Lessons emerged from this experience that established the credibility of the Navrongo model for implementation in nonresearch settings.

Operational indicators of nurses' activities, community responses, and volunteer deployment demonstrate that the replication of Navrongo operations was a success. Moreover, indicators of health-care service volume, coverage, and output suggest that these activities replicated elements of the Navrongo success story. 
Family planning increased in response to program activity. Contraceptive-use prevalence prior to CHPS implementation was estimated to be less than 4 percent. Survey results for 2002 showed that prevalence had climbed to 8.6 percent. A 2004 survey demonstrated that the depressive effect on contraceptive use of distance to supply was eliminated by CHPS activities. Differentials by CHPS exposure suggest that CHPS activity may have a fertility impact. In 2002, family planning practice was reported as 14 percent in CHPS zones and only 4 percent in zones not yet covered by CHPS.

Results from Nkwanta provide evidence that CHPS had an impact on safe-motherhood practices. The odds of having received antenatal care were more than five times greater in service zones where CHPS was implemented compared with rates in "Not Yet CHPS" communities. Similarly, the odds of having received postnatal care were four times greater among women receiving CHPS services compared with women in "Not Yet CHPS" communities when relevant factors were controlled such as religion, wealth, age, ethnicity, marital status, and an asset index ( $\mathrm{p}<0.01$ for both indicators).

Replication of the Navrongo approach was also associated with changes in indicators of infant and child care. For example, the odds of being fully immunized were 2.4 times greater among children living in community-based health planning and services areas compared with the odds for children in "Not Yet CHPS" areas, and parental health-care-seeking behavior was enhanced by CHPS, increasing the odds that febrile children would be treated by a trained paramedic (Awoonor-Williams et al. 2004).

\section{Limitations to direct operational replication}

Although Ghana has a population of only 20 million, it has 82 ethnolinguistic groups. Cultural diversity within Nkwanta District provided organizational challenges illustrative of problems that a national program would encounter in replicating the Navrongo experiment. The process of decentralized pilot trials, adaptive development of strategies, and scaling up within districts was more important to the success experienced in Nkwanta than was the replication of operational details of the Navrongo approach. For example, some Nkwanta communities had as many as five languages and chieftaincies, requiring implementers to rely on organizing the program through secular leaders, such as teachers, politicians, and traders rather than solely through traditional leadership systems. Pilot trials in two zones enabled the Nkwanta team to develop local strategies for overcoming ethnic complexity and building mechanisms for sustaining efforts within district scaling-up activities.

\section{Contrasts with Navrongo findings}

Several elements of the Nkwanta initiative not only have replicated Navrongo effects but also appear to have exceeded levels of impact achieved by the CHFP experiment. Activities that are best addressed by continuous community and household outreach, such as safe-motherhood services, have had a greater initial impact in Nkwanta than in Navrongo. This result may be attributed to Nkwanta's having a unified management system (like most other districts in Ghana), whereas Navrongo has administrative operations for research that are separate from the district health-management team, a separation that weakens the integrity of supervisory support 
for household service operations. Nonetheless, other key elements of the Nkwanta health-care service-delivery system have not acquired the same level of sophisticated technical and computing operations such as those found in Navrongo. In particular, precise tracking of pregnancies and births in Navrongo provides crucial information to community workers that noncomputerized procedures in Nkwanta have yet to achieve.

\section{Building national commitment to change}

The Navrongo/Nkwanta approach to developing community-based care is more complex to describe than to demonstrate, particularly when demonstration involves teams of peer counterparts learning about the initiative by seeing it in action. To achieve this, Navrongo and Nkwanta have shifted their roles from sites for research to districts for orienting regional health administrators and district health-management teams to the community health-service-development process. This demonstration function has been used to develop new demonstration sites in each of the ten regions of Ghana. Thus, the process of learning and demonstration exemplified by Nkwanta has been scaled up throughout Ghana. Extending the geographic range of sites where Navrongo's strategies are demonstrated has increased the credibility of findings from the experiment and verified conclusions from the Nkwanta project (Kuffour et al. 2005). This process was facilitated by national conferences designed to foster review of the implications of the Navrongo/Nkwanta results for national policy and action.

\section{Phase IV: Scaling Up With the CHPS Program}

CHPS is a national process of evidence-based organizational change aimed at removing geographic barriers to health care. To achieve this, CHPS seeks to enable district healthmanagement teams throughout Ghana to adapt and develop approaches to community health care that are consistent with local traditions, sustainable with available resources, and compatible with prevailing needs. The process for pursuing this goal was developed during Phase I in Navrongo and refined in Phase III in Nkwanta. General features of the original Navrongo design serve as guidelines for the national program. Community health nurses, retrained and redeployed as community health officers, are the staff selected to reside in the community to provide health services at the client's doorstep. Community mobilization and participation in program development are central to the program. Although certain elements are common features of CHPS implementation, district teams launching the program are encouraged to adapt strategies to local circumstances, phase in operations over time, and learn through action what works and what fails.

\section{Progress of the CHPS initiative}

Only 22 of Ghana's 110 districts reported their implementation of activities at the beginning of 2001. Eighteen months later 87 districts had taken steps to launch the program. By mid-2004, 105 of the 110 district health-management teams reported having undertaken preliminary planning activities. In 2005, the Government of Ghana split 14 districts for a national 
total of 138. By mid-2005 nearly all district health-management teams had launched some element of the CHPS program.

No district has implemented all activities in a single step in all work zones at once. To shift services from clinic-focused to community-based health care, CHPS requires new mechanisms for establishing community accountability, service quality, and administrative control that are integrated into traditional institutions of village governance. Establishing these mechanisms involves six milestones in organizational change that are phased in zone-by-zone over time: (1) Operational planning for CHPS begins by identifying geographic zones where nurses will be assigned and given responsibility for community health care. Once the districts have been divided into zones, scaling up proceeds by phasing in the posting of nurses. (2) A process of "community entry" is required for building leadership and commitment to collective action. Communication mechanisms build on traditions of collective leadership. For example, durbars are traditional public gatherings involving drumming, dancing, speechmaking, public debate, and open discussion. The durbar tradition was marshaled to build consensus and to foster community ownership of the CHPS program. (3) Community leaders organized the construction or renovation of community health compounds, which function as service-delivery points for community-based health care. Construction is initiated by convening councils of chiefs and elders and meeting with community leaders to mobilize volunteer labor. Community ownership of the program is nurtured by this process. (4) Posting nurses to community health compounds requires investment in equipment and supplies as well as creating new roles for supervisors in supporting logistics arrangements. (5) Prior to the CHPS initiative, nurses were trained in healthcare service delivery without undergoing orientation to community organizational tasks. This gap has been filled with in-service training designed to ensure that nurses assigned to communities can do their work and deal effectively with community institutions. (6) Once the nurses are installed in their communities, community health committees are organized and volunteers are recruited, trained, and deployed to mobilize health-related activities, foster male involvement in family planning, and support the living arrangements of nurses.

\section{The diffusion of innovation}

Analysis of the national CHPS monitoring database shows that district healthmanagement teams participating in peer exchanges between Navrongo and Nkwanta were more than two times more likely than district teams that did not participate to implement the program. This finding lends support to the national effort to scale up the number of demonstration districts and accelerate the pace of exchanges between district teams. Findings indicate that CHPS innovation spreads within districts through the diffusion of community action (Glaser et al. 1983; Mintrom 1997; Rogers 1995). CHPS has been promoted as a series of steps that can be implemented in a few work zones. Success on a small scale in a few zones galvanizes community action and resource mobilization that can be demonstrated to community leaders in neighboring zones, leading to the spread of demand for the program and grassroots political support for its operations. Significant development revenue has been allotted to district assemblies and the discretionary development-funding process. Some districts have developed procedures for training assemblies and district chief executives in setting health priorities and in allocation of 
resources, greatly accelerating the spread and coverage of CHPS (Antwi et al. 2004). This finding suggests a need for policies that complete pilot projects in zones throughout Ghana to catalyze spontaneous organizational change within districts.

\section{National consensus-building}

The CHPS initiative was organized more in the manner of a social movement than as a bureaucratic program. Consensus-building and advocacy were crucial to its success. From the community level to the most senior political leaders and health officials, strategies were focused on building broad consensus by means of decentralized activities. The program's planners recognized that national health policy conferences held to disseminate the findings from the Navrongo experiment were not sufficient to achieve this end, and subsequent meetings were designed to foster discussion and debate about the practical implications of child health and family planning results in the context of scaling up.

A number of principles of consensus-building are demonstrated by CHPS strategies. Organizational change is shown to be highly effective when it is driven by committed individuals who demonstrate that not only is change feasible but also that it is in the interest of the system at large. CHPS fosters district-to-district demonstrations designed to assist implementers in developing a manageable operational change agenda. Throughout the CHPS process, research and evidence were applied by means that respect managers' ownership of the program and enhance the influence of research on decisionmaking. Changing operations from clinic-focused to community-based care involves transformations that affect the entire health-care service system. Often, when members of the community's hierarchy are ignored or bypassed, resistance to change ensues. System pilots, demonstrations, and counterpart orientation are, consequently, more effective strategies for fostering change than are training activities focused on individuals or piecemeal interventions. In the CHPS program, communication tools have been developed for the flow of "bottom-up" lessons learned in a series of newsletters entitled "What works? What fails?" Prepared by a journalist and focused on the information needs of district teams, these newsletters communicate practical experience with CHPS to stakeholders throughout the system. "Top-down" communication is built into policy conferences and guidelines, monitoring and evaluation feedback tools, and other means of communicating to district managers the government's commitment to the CHPS agenda. These means, in turn, are supported by peer-topeer demonstration of CHPS at the district level.

\section{Constraints to scaling up}

The pace of CHPS-sponsored scaling up has been constrained by organizational and resource problems. Although nearly every district in Ghana has joined the scaling-up process, a number of obstacles have emerged. The pace of launching program planning has progressed more rapidly than the pace of implementing community-based services. Although most districts report that they have completed planning, relatively few have launched services. At the beginning of 2003, only 42 percent of the districts had completed the process of community entry in at least one service zone, although community entry is a low-cost strategic component of the program and is simple to implement. By late 2005 this situation had not improved. Moreover, 
facilities are often developed without community involvement, so that the posting of nurses and development of volunteer services lag behind all other milestones. This departure from the CHPS model of community engagement deprives the program of resources for facilities and of the community's sense of ownership of the program. (Qualitative systems appraisals indicate that communities that mobilize resources for the program develop a sense of ownership of its services.) The construction of facilities without community engagement is tantamount to bypassing local support for CHPS (Nyonator 2005b). Diagnostic research clarifies the sources of such problems and is guiding corrective action.

Stakeholders at the national, regional, and district levels of government often misunderstand the CHPS program despite the considerable efforts directed to training, policy directives, conferences, and reports. Frontline workers often amplify managerial concerns about the feasibility of shifting operations from clinics to communities. Nurses who are relocated to communities must leave behind the relative comfort of subdistrict assignments, where their work is routinely supervised and technical demands are minimal. Nurses express concern about the challenges they face, and managers are anxious about embarking upon complicated changes. By contrast, workers participating in the program express satisfaction about their contribution to health-care service improvements and their appreciation of the support that communities render (Sory et al. 2003). Exchanges among peers offset anxieties by building upon positive experience. New policies integrating training of nurses with team demonstration will counteract fear of the unknown and ensure that scaling up improves service quality.

Resources for primary health care in Ghana are severely constrained. Cost analysis for Navrongo shows that CHPS adds \$US1.92 per capita per year in costs to the $\$ 6.80$ per capita currently available for primary health-care services. National economic analyses indicate costs that are low by international standards, but higher than Navrongo estimates. Increasing the coverage of community health services expands individuals' demand for health care that translates into higher costs of pharmaceuticals, fuel, equipment, and supplies. Health-sector reform has conferred authority on district health-management teams, but has not supplied the necessary resources for implementing the general health-service agenda. In the absence of earmarked donor or government funding for CHPS, incremental start-up costs severely constrain efforts to launch the program. In light of the financial and manpower limitations confronting them, many district officials are reluctant to engage in community-entry activities that will arouse public interest in services that the districts are ill-equipped to launch and sustain.

Districts progressing with scaling up have developed creative ways of solving resource constraints. Two have marshaled district assembly support and development funds for augmenting program revenue. Others have raised donations through community activities and faith-based organizations. One district has developed means of solving manpower problems by using "private practitioners," paramedics who are financed by communities rather than salaried Ghana Health Service employees.

Community nurses often are poorly equipped for making independent clinical decisions, having grown accustomed to the continuous technical supervision that subdistrict health centers afford. When they are deployed to communities, they confront major technical challenges immediately. For example, communities typically expect these nurses to have midwifery skills that few are trained to provide. CHPS requires new training protocols and procedures that are not yet in place. 
Evidence indicating that nurses are often anxious about community deployment has raised fundamental questions about manpower policy. Community health nurses are trained in one of four national schools where applicants seek admission, fees are paid by the government, and graduates are deployed to subdistricts by central order. Much of the concern that nurses express derives from their not being native to the communities where they will live and work, where they may not speak the local language, and where they may be compelled to live separately from their families and kin. To address these problems, Navrongo has launched a "community-engaged" approach to training whereby communities select nurse trainees who are sent to a local training center for which the fees are paid by district assemblies and the communities to be served by the trainees. Upon graduation, nurses return home, rather than being sent to a distant post. Positive results of this strategy have generated new policies for the national nurse-training program. Ten new schools are being opened on the Navrongo community-engaged model; ten more are planned with the goal of scaling up the availability of trained providers and improving the quality and social relevance of CHPS policies. This experience attests to the importance of continuous investigation and revision of scaling-up policy as initiatives mature.

\section{CONCLUSION}

The Navrongo experiment demonstrates results that are relevant to international reproductive and child-health policy deliberations. The experiment tested the effect on fertility and child mortality of mobilizing community health services.

Findings demonstrate that family planning programs can have an impact on fertility, even in an impoverished traditional Sahelian setting. Results also indicate, however, that extending access to contraceptive supplies may fail to address adequately the social costs of fertility regulation. Achieving results with family planning services requires developing ways of offsetting the social constraints to contraceptive-method adoption.

The results from Navrongo also show that community health nurse interventions can have a dramatic impact on childhood survival. Community-volunteer approaches, however, have no such impact, a finding that challenges the practicality of the mounting international investment in volunteer-based health programs.

The Ghana health-care-development process demonstrates ways to address simultaneously the global agenda for accelerating access to reproductive and child health services. After a decade of global commitment to the 1994 ICPD Programme of Action, concern is mounting that family planning and reproductive health issues are receding from national health-policy agendas in Africa. Moreover, global commitment to achieving the child-survival MDGs must take into account evidence that these goals are not being met in Africa. Navrongo demonstrates affordable and sustainable means of attaining the ICPD agenda and Millennium Development Goals with existing technologies. Accumulating and using research results was crucial to building this success. The Ghana process was launched in three villages, extended to a district trial, replicated, and scaled up to a national program of community-based health-care reform that now reaches every region of Ghana. The CHPS initiative uses research as a tool for aligning national healthsector policy with vibrant traditions of community leadership, communication, and action. 
Figure 1 Phases in the Ghana Ministry of Health process for organizational change

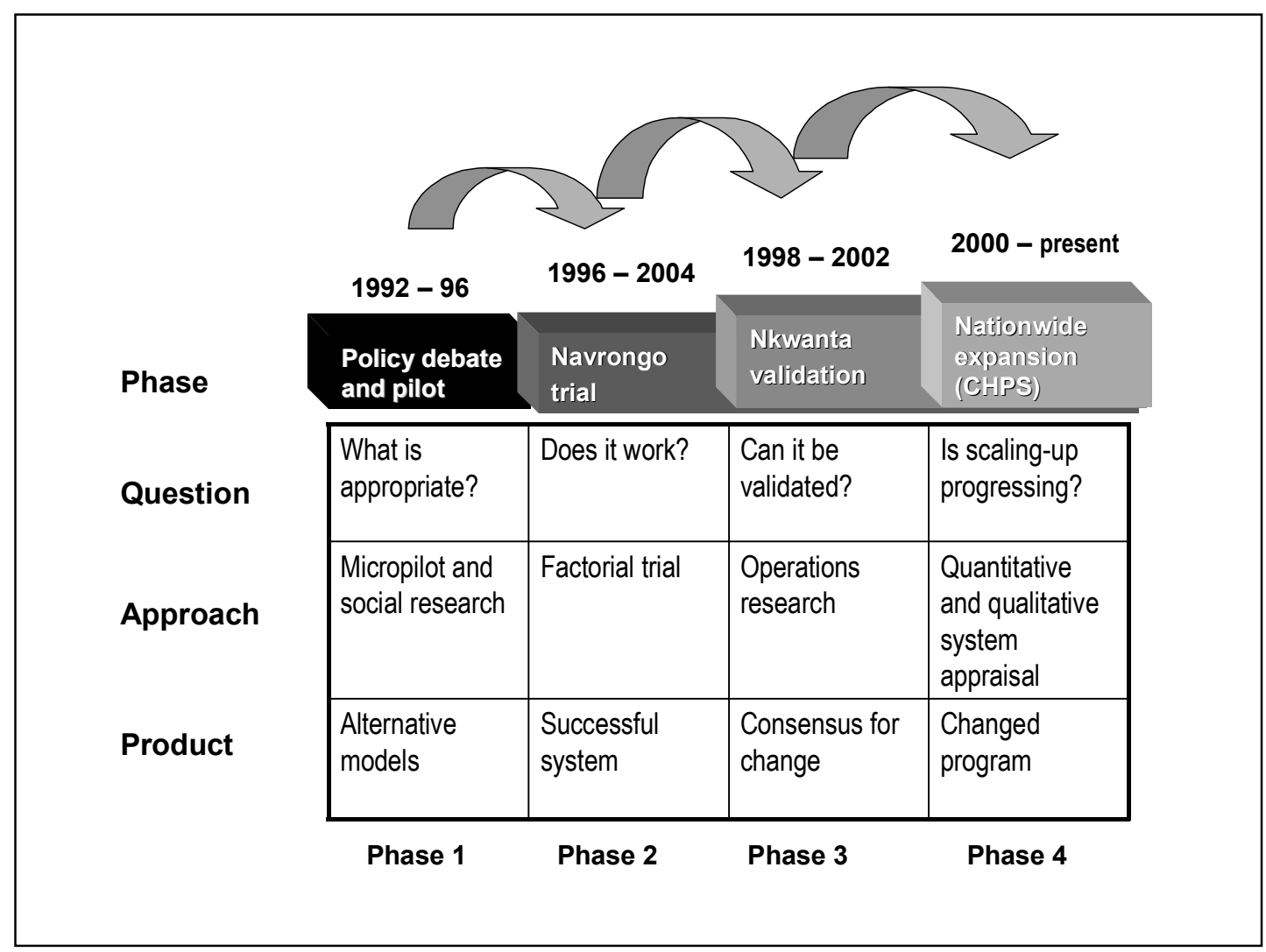

Source: Nyonator et al. (2005a). 
Figure 2 Geographic zones corresponding to Community Health and Family Planning cells in Kassena-Nankana District, Ghana

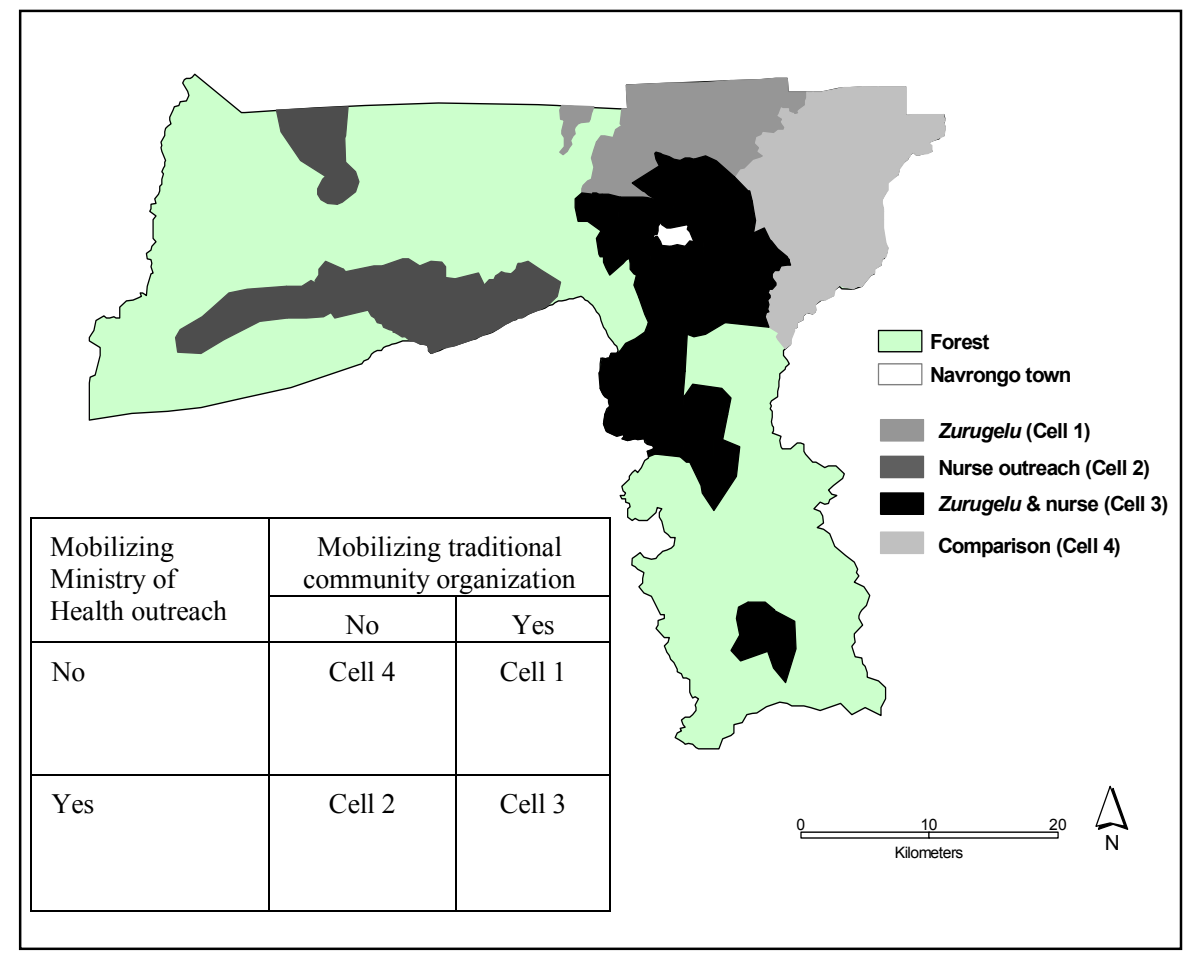

Source: Debpuur et al. (2002). 
Figure 3a Age-specific fertility, combined cell 3, Navrongo, Ghana

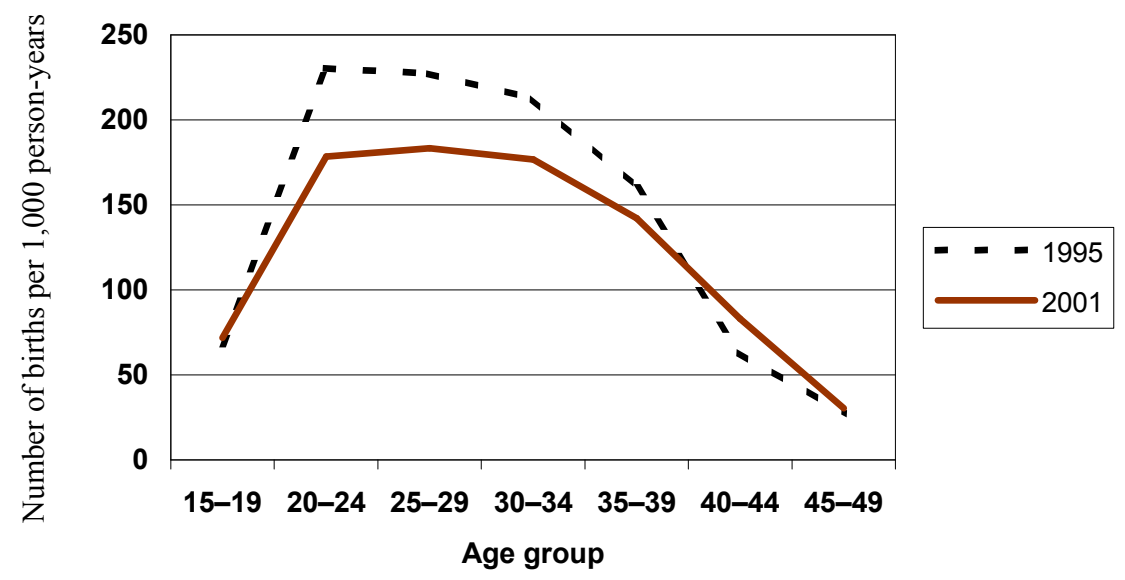

Source: Phillips et al. (2003).

Figure 3b Age-specific fertility, comparison cell 4, Navrongo, Ghana

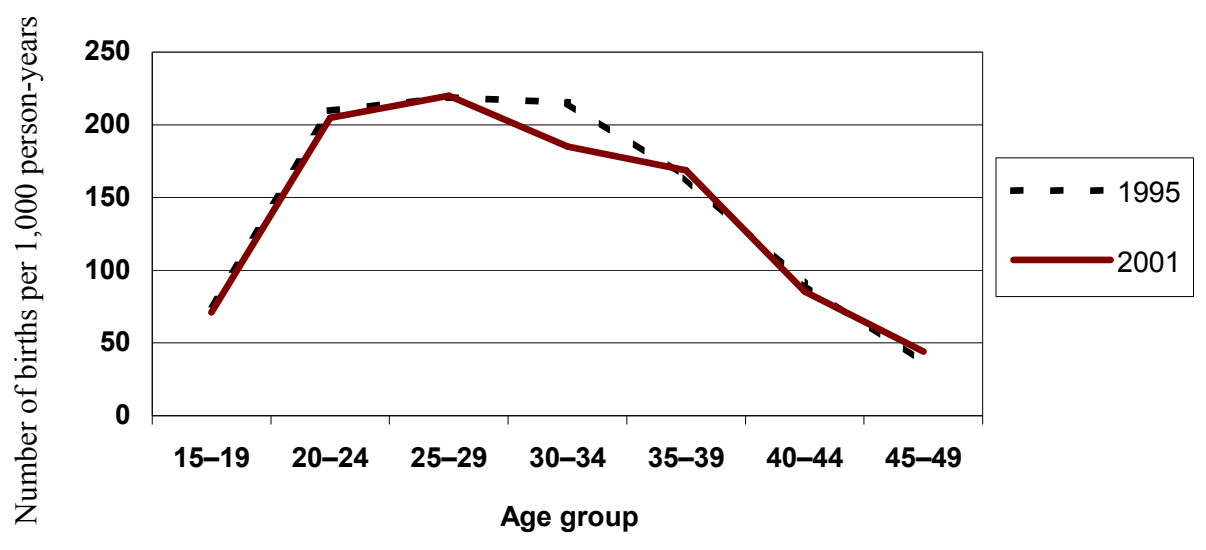

Source: Phillips et al. (2003). 
Figure 4 Trends in under-five mortality compared with MDG targets, Ghana

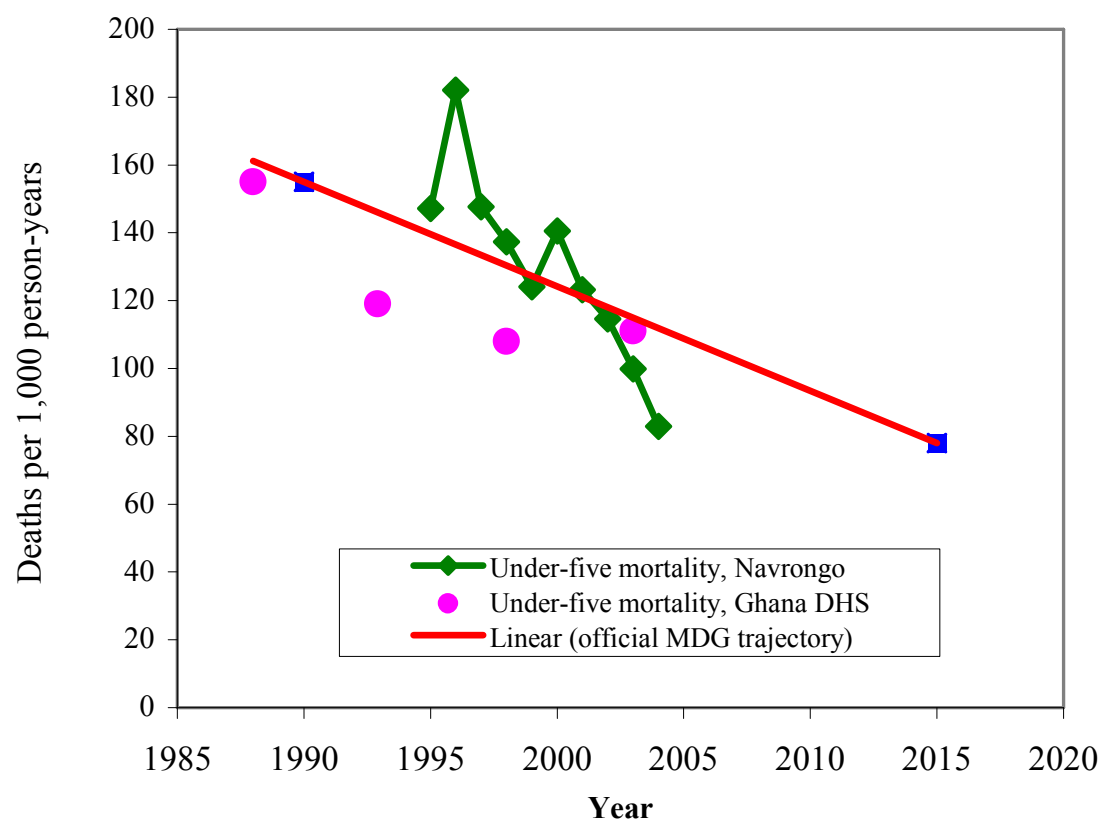

Source: Binka et al. (2005). 
Figure 5 Trends in under-five mortality (5q0), by Community Health and Family Planning cell, Navrongo, Ghana, 1995-2003

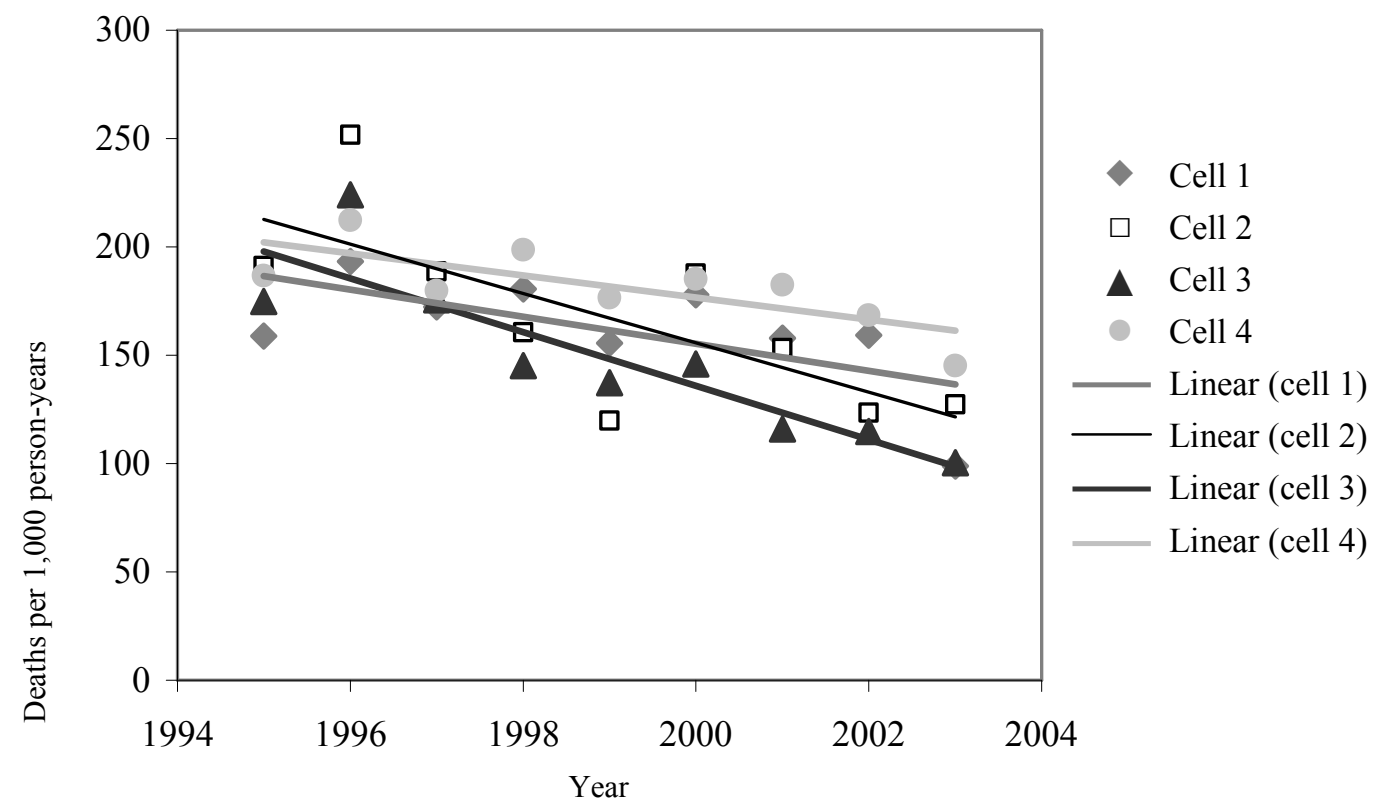


Figure 6 Trends in under-five mortality by experimental cell, Navrongo, Ghana, 1995-2003

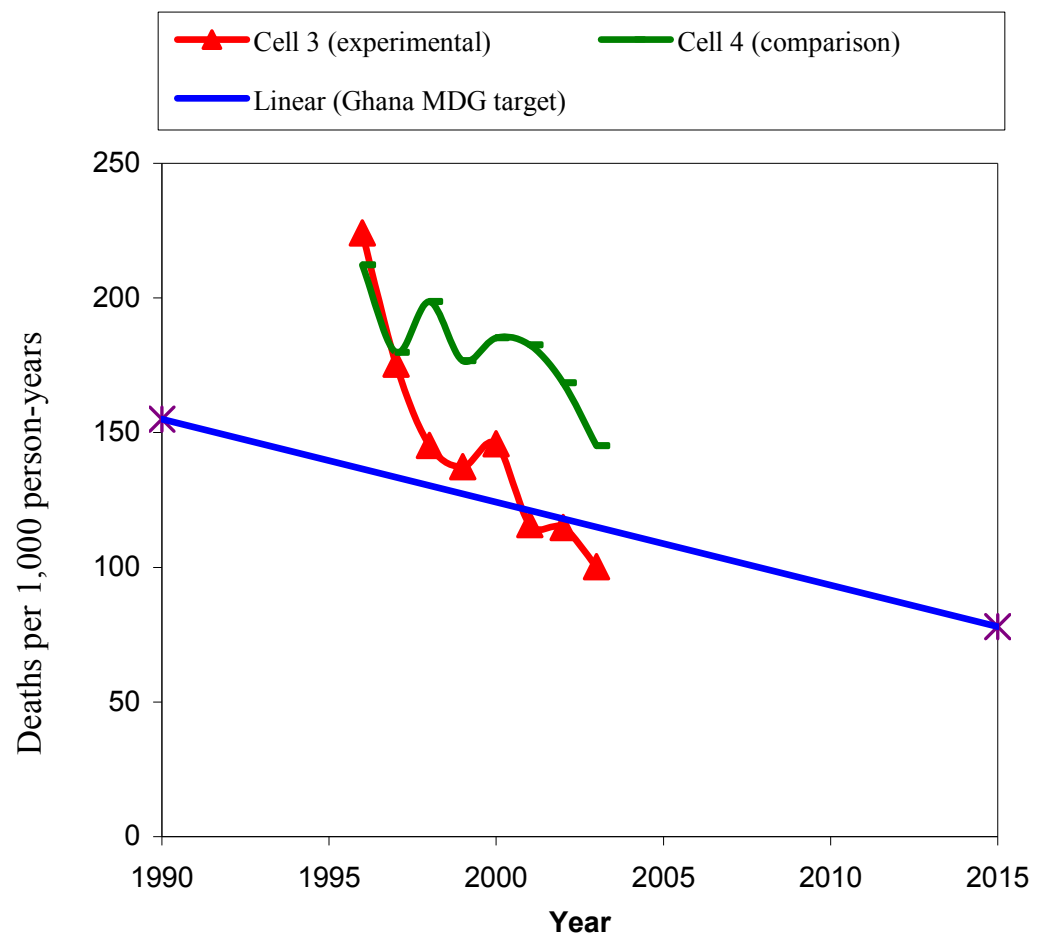

Source: Binka et al. (2005). 


\section{REFERENCES}

Adjei, Sam, K. Senah, and Patricia Cofie. 1995. Study on the Implications of Community Health Workers' Distributing Drugs in Ghana. Accra: Ministry of Health (Ghana) Health Research Unit. Unpublished.

Adongo, Philip, James F. Phillips, Beverly Kajihara, Clara Fayorsey, Cornelius Debpuur, and Fred N. Binka. 1997. "Cultural factors constraining the introduction of family planning among the Kassena-Nankana of northern Ghana." Social Science \& Medicine 45(12): $1,789-1,804$.

Agyepong, Irene and Constance Marfo. 1992. "Is there a place for community health worker programmes in primary health care delivery in Ghana?" Report of the International Evaluation of the Dangbe West District Community Health Workers Programme by the District Health Management Team. Accra: Ministry of Health (Ghana) and UNICEF.

Antwi, Patricia, Frank Nyonator, Tanya C. Jones, Emmanuel Kuffour, and Emerson Arhia. 2004. "The impact of the Community-based Health Planning and Services (CHPS) program on maternal health in the Abura-Asebu Kwamankese District in Ghana." Paper Presented at the Annual Meeting of the Population Association of America, Boston, 1-3 April.

Awoonor-Williams, John Koku, Ellie S. Feinglass, Rachel Tobey, Maya N. Vaughan-Smith, Frank K. Nyonator, and Tanya C. Jones. 2004. "Bridging the gap between evidencebased innovation and national health-sector reform in Ghana." Studies in Family Planning 35(3): 161-177.

Bawah, Ayaga Agula, Patricia Akweongo, Ruth Simmons, and James F. Phillips. 1999. "Women's fears and men's anxieties: The impact of family planning on gender relations in northern Ghana.” Studies in Family Planning 30(1): 54-66.

Berman, P.A., Davidson R. Gwatkin, and S.E. Burger. 1987. "Community-based health workers: Head start or false start towards health for all?" Social Science \& Medicine 25(5): 443459.

Binka, Fred N., Alex Nazzar, and James F. Phillips. 1995. "The Navrongo Community Health and Family Planning Project.” Studies in Family Planning 26(3): 121-139.

Binka, Fred N., Frank Kubaje Adazu, Martin Adjuik, L.A. Williams, Christian Lengeler, H.H. Maude, George Armah, Beverly Kajihara, J.H. Adiamah, and Peter G. Smith. 1996. "Impact of permethrin-impregnated bed nets on child mortality in the Kasena-Nankana district, Ghana: A randomized controlled trial." Tropical Medicine and International Health 1(2): 147-154.

Binka, Fred N., Pierre Ngom, James F. Phillips, Kubaje Adazu, and Bruce B. MacLeod. 1999. "Assessing population dynamics in a rural African society: The Navrongo Demographic Surveillance System.” Journal of Biosocial Science 31: 373-391. 
Binka, Fred N., Ayaga A. Bawah, and James F. Phillips. 2005. "Rapid achievement of the child survival Millennium Development Goals in a rural remote district of northern Ghana." Unpublished.

Bledsoe, Caroline H., Allan G. Hill, Umberto D’Alessandro, and Patricia Langerock. 1994. "Constructing natural fertility: The use of Western contraceptive technologies in rural Gambia." Population and Development Review 20(1): 81-113.

Bryce, Jennifer, Shams el Arifeen, George Pariyo, Claudio F. Lanata, Davidson Gwadkin, JeanPierre Habicht, and the Multi-Country Evaluation of IMCI Study Group. 2003. "Reducing child mortality: Can public health deliver?” Lancet 362(July): 159-164.

Caldwell, John C. 1997. "The impact of the African AIDS epidemic." Health and Transition Review 7(Supplement 2): 169-188.

Caldwell, John C. and Pat Caldwell. 1987. "The cultural context of high fertility in sub-Saharan Africa." Population and Development Review 13(3): 409-437.

- 1988. "Is the Asian family planning program model suited to Africa?" Studies in Family Planning 19(1): 19-28.

Debpuur, Cornelius, James F. Phillips, Elizabeth F. Jackson, Alex Nazzar, Pierre Ngom, and Fred N. Binka. 2002. "The impact of the Navrongo project on contraceptive knowledge and use, reproductive preferences, and fertility." Studies in Family Planning 33(2): 141-164.

Easterlin, Richard A. 1978. "The economics and sociology of fertility: A synthesis.” In Historical Studies of Changing Fertility. Ed. C. Tilly. Princeton: Princeton University Press.

Easterlin, Richard A. and E.M. Crimmins. 1985. The Fertility Revolution: A Supply-Demand Analysis. Chicago: University of Chicago Press.

Ghana Statistical Services (GSS), Noguchi Memorial Institute for Medical Research (NMIMR), and ORC Macro. 2004. Ghana Demographic and Health Survey 2003. Calverton, MD: GSS, NMIMR, and ORC Macro.

Ghana Vitamin A Supplementation Trials (VAST) Study Team. 1993. "Vitamin A supplementation in northern Ghana: effects on clinical attendance, hospital admissions, and child mortality." Lancet 342(8,862): 7-12.

Glaser, E.M., H.H. Abelson, and K.N. Garrison. 1983. Putting Knowledge to Use: Facilitating the Diffusion of Knowledge and the Implementation of Planned Change. San Francisco: Jossey-Bass Publishers.

Habicht, Jean-Pierre, C.G. Victora, and J. Patrick Vaughan. 1999. "Evaluation designs for adequacy, plausibility, and probability of public health programme performance and impact." International Journal of Epidemiology 28: 10-18.

Hill, Allan. 1993. "Trends in childhood mortality." In Demographic Change in Sub-Saharan Africa. National Research Council, Washington, DC: National Academic Press. Pp. 153217. 
Knippenberg, R., D. Levy-Bruhl, R. Osseni, K. Drame, A. Soucat, and C. Debeugny. 1990. The Bamako Initiative: Primary Health Care. New York: UNICEF.

Kuffour, Emmanuel, Patricia Antwi, and Frank Nyonator. 2005. "Program evaluation when there is purposive placement: An example of a social program in Ghana.” Unpublished.

McPake, B., K. Hanson, and Anne Mills. 1993. "Community financing of health care in Africa: An evaluation of the Bamako Initiative." Social Science \& Medicine 36(11): 1,3831,395 .

Ministry of Health of the Republic of Ghana. 1998. A Profile of Health Inequities in Ghana. Accra: Ministry of Health.

Mintrom, Michael. 1997. "Policy entrepreneurs and the diffusion of innovation." American Journal of Political Science 41: 738-770

Nazzar, Alex, Philip B. Adongo, Fred N. Binka, James F. Phillips, and Cornelius Debpuur. 1995. "Developing a culturally appropriate family planning program for the Navrongo experiment." Studies in Family Planning 26(6): 307-324.

Nicoll, Angus, Ian Timaeus, Rose-Mary Kigadye, Gijs Walraven, and Japhet Killewo. 1994. "The impact of HIV-1 infection on mortality in children under five years of age in subSaharan Africa: A demographic and epidemiological analysis.” AIDS 8(7): 99-105.

Nyonator, Frank K., John Koku Awoonor-Williams, James F. Phillips, Tanya C. Jones, and Robert A. Miller. 2005a. "The Ghana Community-based Health Planning and Services initiative: Fostering evidence-based organizational change and development in a resource-constrained setting." Health Policy and Planning 20(1): 25-34.

Nyonator, Frank K., Tanya C. Jones, Robert A. Miller, James F. Phillips, and John Koku Awoonor-Williams. 2005b. "The application of qualitative systems analysis for guiding a scaling-up initiative in Ghana." International Quarterly of Community Health Education. Forthcoming.

Pence, Brian Wells, Philomena Nyarko, James F. Phillips, and Cornelius Debpuur. 2005. "The Effect of Community Nurses and Health Volunteers on Child Mortality: The Navrongo Community Health and Family Planning Project." Policy Research Division Working Paper No. 200. New York: Population Council.

Phillips, James F., Elizabeth F. Jackson, Ayaga A. Bawah, and Cornelius Y. Debpuur. 2003. "The fertility impact of the Navrongo Project." Paper presented at the Annual Meeting of the Population Association of America, Minneapolis, 1-3 May.

Pritchett, Lant. H. 1994. "Desired fertility and the impact of population policies." Population and Development Review 20(1): 1-55.

Rogers, Everett M. 1995. Diffusion of Innovations. Fourth edition. New York: Free Press. 
Simmons, George B. 1992. "Supply and demand, not supply vs. demand: appropriate theory for the study of effects of family planning programmes on fertility." In Family Planning Programmes and Fertility. Eds. James F. Phillips and John A. Ross. Oxford: Clarendon Press. Pp. 59-77.

Sory, Elias K., Tanya C. Jones, Frank K. Nyonator, and James F. Phillips. 2003. "Grassroots mobilization to accelerate the introduction of community-based health service delivery in Ghana: Strategic assessment of the CHPS program in the central region of Ghana." Paper presented at the Annual Meeting of the American Public Health Association, San Francisco, 15-19 November.

Timaeus, I.M. 1997. "Age pattern of mortality in sub-Saharan Africa: An initial study of the impact of AIDS." Paper presented at the Annual Meeting of the Population Association of America, Washington, DC, 28-30 March.

- 1999a. "Mortality in sub-Saharan Africa." In Health and Mortality: Issues of Global Concern. Eds. J. Chamie and R.L. Cliquet. New York: United Nations Population Division.

- 1999b. "Adult mortality in Africa in the era of AIDS." In The African Population in the $21^{\text {st }}$ Century. Volume 2. Dakar, Senegal: Union for African Population Studies. Pp. 377395.

UNICEF. 1991. “The Bamako Initiative: A progress report.” New York: UNICEF. Unpublished.

- 1995. The Bamako Initiative: Rebuilding Health Systems. New York: UNICEF, The Bamako Initiative Management Unit.

Van de Walle, Etienne and Andrew Foster. 1990. "Fertility Decline in Africa: Assessment and Prospects." World Bank Technical Paper No. 125. Africa Technical Department Series. Washington, DC: World Bank.

Victora, C.G., Jean-Pierre Habicht, and Jennifer Bryce. 2004 "Evidence-based public health: Moving beyond randomized trials." American Journal of Public Health 94(3): 400-405.

World Bank. 1993. World Development Report: Investing in Health. New York: Oxford University Press.

. 2003. Making Services Work for Poor People, The 2004 World Development Report. New York: Oxford University Press. 